\title{
Opinion: Aggravated food insecurity in COVID-19 era: quality seed flow of adapted and nutrient- dense varieties is central to the recovery equation in the drylands
}

Essegbemon Akpo*1,2 (akpo.essegbemon@gmail.com ; E.Akpo@cgiar.org), Chris O. Ojiewo ${ }^{1}$ (C.Ojiewo@cgiar.org), Mequanint B. Melesse ${ }^{1}$ (M.Melesse@cgiar.org), Ganga Rao ${ }^{1}$ (N.Gangarao@cgair.org), James Mwololo ${ }^{1}$ (J.Mwololo@cgiar.org), Eric Manyasa ${ }^{1}$ (E.Manyasa@cgiar.org), Henry Ojulong ${ }^{1}$ (H.Ojulong@ @ cgiar.org), Rebbie Harawa ${ }^{1}$ (R.Harawa@ cgiar.org), Rajeev K. Varshney ${ }^{1}$ (r.k.varshney@cgiar.org)

\footnotetext{
${ }^{1}$ International Crops Research Institute for the Semi-Arid Tropics, Patancheru 502 324, Telangana, India

${ }^{2}$ Ecole de Gestion et de Production Végétale et Semencière, Université Nationale d'Agriculture, BP 43 Kétou, Benin * Corresponding author
}

\begin{abstract}
The COVID-19 pandemic has disrupted every area of our daily activities and businesses. After the health crisis, the food crisis is the next battle to encounter, which will need to mobilize all energies to maintain social security and protect the citizens of the world. For sustained support and recovery of rural and urban populations, especially in the dryland areas of Sub-Saharan Africa, seed of the welladapted, nutrient dense varieties should flow. The solution of quality seed flow equation is complex and involves several intervention areas, e.g., adapted and modern groundnut, chickpea, pigeonpea, sorghum and finger millet varieties, sustainable and long term approaches leveraging various seed production and delivery models, remote information and knowledge dissemination systems, digital seed production and delivery roadmaps, digitized variety release and promotion processes, smart food campaigns and trainings to promote good utilization of nutrient dense crops.
\end{abstract}

Key words

COVID-19; Vulnerable communities; Sustainable recovery approaches; Dryland agriculture; food and nutrition security

The world is facing its most challenging and unprecedented threat in modern history with COVID-19 pandemic. The COVID-19 has disrupted every area of our daily activities and businesses. The virus at some point in time outpowered the existing health systems of the heavily hit countries, including developed countries like USA, Italy, Spain, United Kingdom and France. Even with all the existing means, developed countries were seriously tested and the number of lives lost each day is heart breaking. The saddest part of the COVID-19 global threat is that family members cannot even be by the side of their loved ones during their last breath.

Beyond the health systems, COVID-19 has adversely affected agriculture and food systems. The World Food Program (WFP) projected that the number of people facing chronic acute food insecurity is bound to double to 265 million in 2020 as opposed to 135 million in 2019 [1]. FAO [2] has estimated to 820 million hungry people worldwide in 2018 . Unfortunately, the majority of these people live in the developing countries. The situation is even worse in the drylands, the areas of the globe naturally facing many uncertainties [3] to which COVID-19 is adding much more. These regions are characterized by low and erratic rainfalls as low as $200 \mathrm{~mm} / \mathrm{year}$, degraded soils, low crop productivity and production, animal feed shortage, and on top of it, recurrent desert locust and fall armyworm invasions [4],[5].

After the health crisis, the food crisis is the next battle to encounter, which will need to mobilize all energies to maintain social security and protect the citizens in every country. COVID-19 is expected to heavily jeopardize the realization of sustainable development goals (SDG), most importantly SDG $1,2,3,4$ and 8 in most countries, unless innovative, sustained and well-fit agricultural interventions are deployed for food and nutritional security toward vulnerable communities in the dryland areas of subSaharan Africa. COVID-19 is very detrimental to infected people of all ages especially those with preexisting medical conditions, e.g. diabetes, obesity, severe and chronic lung disease, heart conditions, severe asthma, immuno-compromised individuals, chronic liver disease, kidney disease, etc. In the same vain, many people living in the drylands already have natural pre-existing conditions in addition to malaria, HIV and malnutrition that weaken their ability to recover from tough challenges imposed by COVID-19. Therefore, if sustained interventions are not put in place, the already vulnerable communities are set to crumble under the heavy burden of food and nutrition insecurities. We should 
win this war by adapting available and innovative agricultural technologies and resources that research and development have built over years.

Response and recovery from emergencies involve setting out mechanisms for business to continue operating the closest possible to normal [6]. This involves processes of planning, testing and restoring operations where research and development have major roles. Under normal circumstances, research and development organizations have been actively working to enhance food and nutrition security in urban and rural areas by facilitating access to improved varieties by smallholder farmers using various seed delivery models. In the context of crisis, especially a global pandemic like COVID-19, the research and development communities need to change gears and embrace much responsive practices. For sustained support and recovery of communities, especially in the dryland areas of Sub-Saharan Africa, seed of the well-adapted, nutrient dense varieties should continue to flow. The solution of quality seed flow equation is complex and involves several intervention areas, delineated below.

Awareness campaigns, spearheaded by Governments and many other development organizations, are advocating balanced and rich diets as key means to cope with and eventually beat COVID-19 virus. Good health and subsequent strong immune system are major assets to beat COVID-19 virus. For communities to eat healthy and rich, adapted and modern crop technologies are best bet they need and should have in their plates. Over the past decade, the International Crops Research Institute for the Semi-Arid Tropics (ICRISAT) jointly with its partners empowered those living in the semi-arid regions, especially smallholder farmers, to overcome poverty, hunger, malnutrition and a degraded environment through more efficient and profitable climate smart agricultural technologies. New high-yielding varieties of groundnut, chickpea, pigeonpea, sorghum and finger millet have been released in subSaharan Africa that produce between 30-90\% yield advantage over existing old ones, grown by farmers [7]. The groundnut, chickpea, pigeonpea, sorghum and finger millet varieties have key traits to support sustained recovery of communities in the drylands. These varieties possess one or more of the traits like high calcium, iron, zinc, high protein, high oleic oil and low aflatoxin, early maturity, drought-tolerance, disease resistance, and insect tolerance, preferred consumer taste and short cooking time. Some examples of these technologies in selected countries include:

- Finger millet variety NAROMIL 4 released in Uganda in 2017 that is early maturing (85 days), good malting quality, blast and drought tolerant, yielding 3-5t/ha.

- Sorghum Dekeba released in Ethiopia with good grain, drought tolerant, early maturity, 3.7-4.t/ha yield, maturing in 120 days

- Groundnut variety Naronut 1R, released in 2019 in Uganda, that is extra early, drought tolerant, rosette and leafspot resistant, small-medium size, red kernel, easy to harvest and shell, sweet in taste, 2.0$2.5 \mathrm{t} / \mathrm{ha}$ yield, maturing in 75-80 days

- Chickpea variety Ukiriguru 1, released in 2011 in Tanzania, that is drought tolerant, fusarium wilt resistant, high adaptability, 1.5-2.8t/ha yield, maturing in 75-90 days

- Chickpea Chania desi 2, released in 2013 in Kenya, that is heat tolerant, fusarium wilt resistant, good for canning, 1.2-3.2t/ha yield, maturing in 75-90 days

- Pigeonpea MPPV 4, released in 2018 in Zambia, pest tolerant, medium duration, Fusarium wilt resistant, drought tolerant, possess ratoonability, 2.5t/ha yield potential, maturing in 155-175 days

In addition to emergency seed models usually implemented (e.g. seed voucher, seed fair, direct seed distribution, direct cash support), sustainable and long term approaches that involve leveraging various seed production and delivery models should be prioritized [7],[8],[9]. Such models would include:

- $\quad$ small seed pack: affordable seed in small amount, best-fit to small farmer budget

- community-based seed production: proximity seed access to farmers in remote areas

- local seed business promotion: organized community seed producers into business entities

- seed revolving fund: incentives to seed companies and other seed value chain actors to enhance seed production, marketing and delivery

- quality declared seed: quality seed that undergoes reduced quality check protocols, available at affordable price, marketed within community, e.g. within ward

- village/community seed bank: community level seed saving initiative

- gender-sensitive seed systems: women seed producers deliberately facilitated to start seed business 
- nutrition-focused seed systems: promotion of nutrition dense varieties and utilization by farming communities

- agriculture primary school seed dissemination: Agriculture primary school primary schools engaged in varietal demonstrations

In Ethiopia, Kenya, Tanzania and Uganda often hit by disasters, the combination of these seed delivery models with joint efforts by government and development organizations, farmers' adoption of improved varieties is over 30\%, and the momentum should be enhanced further [10],[11],[12]. Working actively with country seed value chain actors to increase the number of seed producers and seed access points for climate-smart, nutrient dense varieties for communities across the drylands and particularly in sub-Saharan Africa remains a high-priority. In Tanzania for example, various seed companies and farmer organizations that have embraced production of seed of improved varieties of these crops, are good seed access points for COVID-19 affected communities. Specific examples are Alssem Company Limited, Lima Africa Company Limited, Temnar Company Limited, Dodoma Agricultural Seed Production Association (DASPA), Agriseed Technologies Ltd, Mbozi Highland Economic Group Company Limited (MHEG) in different regions of Tanzania.

ICT technologies should be leveraged to complement these efforts and ensure more reach. With the readily available ICT tools across the globe, remote information and knowledge dissemination systems are critical to keep communities updated and timely informed. Through this approach, remote monitoring of seed interventions and data collection can be achieved.

Digital seed production and delivery roadmaps (DSR) should be critically considered. Using hind/in/foresight data to inform such process, DSR is a planning and delivery tool that helps the country to know its needs for various seed classes. DSR would be critical in handling early-generation seed supply challenge, channeling commercial seed through formal seed (farmer-based small-scale seed enterprises, private seed companies) and informal seed (farmer group, farmer organizations, individual farmers, village seed bank) supply systems.

The digitization of variety release and promotion processes should also be prioritized. Remote processing of paperwork and limited contacts between committee members is an option to fast track variety release and promotion process.

Smart food campaigns and trainings that promote good utilization of nutrient dense crops deployed in communities would enhance nutritional status of vulnerable people and fight hidden hunger. Facilitating a close collaboration between, public, private and development organization will narrow the gaps between value chain actors and secure business market for smallholder farmers. Diversifying diets through new cooking recipes would heal score of stunting children, and women.

In conclusion, while we agree that interventions to support and enhance seed flow should be now for community relief in the short term, the focus should go beyond the emergency response and target more sustainable support practices in medium and long terms. COVID-19 pandemic is our generation challenge and we ought to answer this historic call effectively with all available technologies and resources for the well-being of our people, specifically those in the already very challenging dryland areas.

\section{Conflict of Interest statement}

The authors declared that they have no conflict of interest

\section{References}

[1] WFP. (2020). https://www.wfp.org/news/covid-19-will-double-number-people-facing-food-crisesunless-swift-action-taken. Accessed on 06/05/2020.

[2] FAO. (2020). https://www.who.int/news-room/detail/15-07-2019-world-hunger-is-still-not-goingdown-after-three-years-and-obesity-is-still-growing-un-report. Accessed on 06/05/2020

[3] Bantilan M. C. S., Anand Babu, P., Anupama, G. V., Deepthi, H., \& Padmaja, R. (2006). Dryland agriculture: Dynamics, challenges and priorities. Research Bulletin no. 20. Patancheru 502 324, Andhra Pradesh, India: International Crops Research Institute for the Semi-Arid Tropics. 32 pp. ISBN 92-9066-496-7. Order code RBE 020.

[4] FAO. (2017). http://www.fao.org/emergencies/fao-in-action/stories/stories-detail/en/c/889846/. Accessed on 06/05/2020. 
[5] Dar, W. D. (2011). Dryland agriculture in semi-arid tropics: constraints and opportunities. Indian Journal of Dryland Agriculture, Research and Development 26(1): 1-7.

[6] Maxwell, D., Sim, A., Mutonyi, M., \& Egan, R. (2007). Emergency Food Security Interventions: A state of the art review. Feinstein International Center.

[7] Monyo, E., \& Varshney, R. (eds) (2016). Seven seasons of learning and engaging smallholder farmers in the drought-prone areas of sub-Saharan Africa and South Asia through Tropical Legumes, 2007-2014. Patancheru, India: International Crops Research Institute for the SemiArid. Patancheru 502 324, Andhra Pradesh, India.

[8] FAO. (2010). Seed in emergencies. A technical handbook. Food and Agriculture Organization of the United Nations (FAO). Rome. Italy.

[9] Vernooy, R., Shrestha, P., \& Sthapit, B. (2015). Community seed bank. Origins, evolutions and prospects. Bioversity International.

[10] Jelliffe, J. L., Bravo-Ureta, B. E., Deom, C. M., \& Okello, D. K. (2018) Adoption of High-Yielding Groundnut Varieties: The Sustainability of a Farmer-Led Multiplication-Dissemination Program in Eastern Uganda. Sustainability, 10, 1597.

[11] Kaliba, A. R., Mazvimavi, K., Gregory, T. L., Mgonja, F. M., \& Mgonja, M. (2018). Factors affecting adoption of improved sorghum varieties in Tanzania under information and capital constraints. Agricultural and Food Economics 6(18): v1-21.

[12] Timu, A. G., Mulwa, R., Okello, J., \& Kamau, M. (2014). The role of varietal attributes on adoption of improved seed varieties: the case of sorghum in Kenya. Agriculture \& Food Security, 3(9): 17 